\title{
Impact of Interspace Distraction on Fusion and Clinical Outcomes in Anterior Cervical Discectomy and Fusion: A Longitudinal Cohort Study
}

\author{
Michael H. Lawless ${ }^{1}$, Elise J. Yoon ${ }^{1}$, Jacob M. Jasinski ${ }^{1}$, Joseph Gabrail ${ }^{1}$, \\ Noah Jordan ${ }^{2}, \operatorname{Karl~Kado}^{3}$, Doris Tong ${ }^{1}$, Teck M. Soo ${ }^{1}$, Daniel A. Carr ${ }^{1}$ \\ ${ }^{I}$ Division of Neurosurgery, Ascension Providence Hospital, College of Human Medicine, Michigan State University, Southfield, MI, USA \\ ${ }^{2}$ West Virginia School of Osteopathic Medicine, Lewisburg, WV, USA \\ ${ }^{3}$ Department of Radiology, Ascension Providence Hospital, College of Human Medicine, Michigan State University, Southfield, MI, USA
}

Study Design: Longitudinal cohort study.

Purpose: To determine the effect of change in interspace height on fusion and postoperative neck pain.

Overview of Literature: The optimal height of a cervical interbody device (cage) in anterior cervical discectomy and fusion (ACDF) is not well defined. In addition, the effect of interspace distraction on fusion and postoperative neck pain remains unclear.

Methods: We retrospectively reviewed the charts of consecutive patients who underwent one- or two-level ACDF using polyetheretherketone cages by multiple surgeons from January 2015 to June 2016. We excluded patients younger than 18 years old, patients who had prior surgery at the same level (s), those with two-stage procedures, and those with less than 3 months of followup. Fusion was determined using the "Song" criteria. Ordinal regression was used to determine predictors of fusion. Patient-reported outcomes (PRO) were analyzed.

Results: We identified 323 consecutive patients. Twenty-two patients met the exclusion criteria. A total of 435 operative levels were included in the 301 remaining patients. Interspace fusion did not significantly vary by increasing interspace height with fusion rates between $76.2 \%$ and $82.8 \%$ at a mean follow-up of $17.9 \pm 12.6$ months. The effect of an increase in interspace height and neck pain PRO was available for 163 patients who underwent one-level ACDF at a mean follow-up period of $16.2 \pm 13.1$ months. We found no significant difference in fusion rate or neck pain score with increasing interspace height from 1 to $8 \mathrm{~mm}$. Ordinal regression demonstrated no significant predictors of fusion.

Conclusions: Interspace distraction from 1 to $8 \mathrm{~mm}$ did not result in significantly different pseudarthrosis rates or postoperative neck pain.

Keywords: Cervical spine; Spinal fusion; Cage height; Neck pain

\section{Introduction}

Since the inception of anterior cervical discectomy and fusion (ACDF) by Smith and Robinson [1] in 1958, this approach has been a dependable technique in a spine surgeon's armamentarium to treat cervical degenerative

Received Dec 14, 2020; Revised Jun 25, 2021; Accepted Jul 13, 2021

Corresponding author: Michael H. Lawless

Division of Neurosurgery, Ascension Providence Hospital, 16001 West Nine Mile Rd., Southfield, Michigan, 48075, USA

Tel: +1-248-569-7745, Fax: +1-248-569-4539, E-mail: lawles20@msu.edu 
pathology. In recent years, the use of cervical interbody devices (cages) in place of cortical or cortical-cancellous allografts has become commonplace [2]. The size of the cage inserted largely depends on patient-specific anatomy. However, varying degrees of interspace distraction can be accomplished. Interspace distraction is routinely used for intraoperative visualization, restoring cervical lordosis, and providing indirect decompression of the neural foramina. It has been demonstrated that disk space distraction with an oversized cage can lead to nonunion and increased postoperative neck pain via facet joint distraction and muscle spasm $[3,4]$. However, the optimal amount of interspace distraction in ACDF remains unclear. Our study aimed to evaluate the relationships between interspace height distraction, rate of fusion, and postoperative neck pain in ACDF.

\section{Materials and Methods}

This study was approved by the Ascension Providence Institutional Review Board (approval no., 803851-1). The requirement for informed consent from individual patients was waived due to the retrospective design and minimal risk to participants in this study. We conducted a retrospective chart review of consecutive patients who underwent one- or two-level ACDF for degenerative indications (cervical disk degeneration, disk herniation, central stenosis, foraminal stenosis, and/or myelopathy) by multiple surgeons Ascension Providence Hospital from January 2015 to June 2016. Patients were excluded if they were less than 18 years old, had previous surgery at the operative level(s), underwent a planned second-stage posterior instrumentation during follow-up, or had less than three months of follow-up.

The primary outcome was radiographic fusion as measured by the "Song" criteria with lateral cervical spine $\mathrm{X}$-rays, including both flexion and extension views [5]. Fusion was recorded if there was $1 \mathrm{~mm}$ or less of interspinous motion at the operative segment when magnified to $150 \%$ and with $4 \mathrm{~mm}$ or more of superjacent interspinous motion above the operative segment [5]. If computed tomography $(\mathrm{CT})$ scans were available, these were reviewed in place of an X-ray. In those cases, fusion was determined by the presence of continuous bony trabeculae across the interspace in CT images. Preoperative disk space height was determined by preoperative cervical X-ray, magnetic resonance imaging, and $\mathrm{CT}$, if available. The central disk height was measured preoperatively and postoperatively, at last follow-up, to determine the change in interspace height in millimeters. An independent board-certified neuroradiologist verified the interpretations of radiographs. The secondary outcomes were patient-reported outcomes (PRO) as measured by the quality of life 12item Short Form Health Survey (SF-12), Neck Disability Index (NDI), and neck Visual Analog Scale (VAS) score. The value collected at the most recent time point was used as the final PRO.

We collected data on patients' sex, smoking status, body mass index (BMI), diabetes mellitus, operative level(s), pre- and postoperative interspace height, and cage height. Outcomes were collected during in-person clinic visits and phone interviews for up to 5 years postoperatively.

Descriptive, correlative, and regression statistics were used. As PRO was measured per patient, two-level ACDF patients were excluded from PRO analyses to avoid confounding two different interspace distraction values with the PRO. Pearson's correlation was used to correlate the PRO with the increased disk space height due to distraction. Ordinal regression was used to determine whether interspace distraction is a significant predictor of fusion. Age, diabetes, smoking, sex, BMI, and distraction height were included in the model. A $p<0.008$ was considered significant with Bonferroni's correction.

A standard Smith-Robinson technique was used to access the desired cervical vertebral level(s) [1]. A horseshoe-shaped, polyetheretherketone (PEEK) cage or zero-profile integrated screw-PEEK construct (K2M Inc., Leesburg, VA, USA) was used. After exposure and confirmation of the appropriate vertebral level(s), an annulotomy was created, and disk space distraction was performed using Caspar distraction pins, placed in the center, midbody at the operative level (Aesculap Inc., Center Valley, PA, USA). Discectomy was performed using a standard microsurgical technique with a combination of angled curettes and high-speed burr, avoiding excessive removal of the subchondral bone to preserve the endplates. Trial disk spacers were placed in the intervertebral space to determine the ideal cage size. The PEEK cage was filled with demineralized bone matrix allograft in addition to local autograft and then placed in the intervertebral space under compression. A low-profile titanium alloy plate and self-tapping titanium alloy screws (Zimmer Biomet Spine Inc., Westminster, CO, USA) were applied when used with the horseshoe-shaped PEEK cage. Fixed-angle screws 

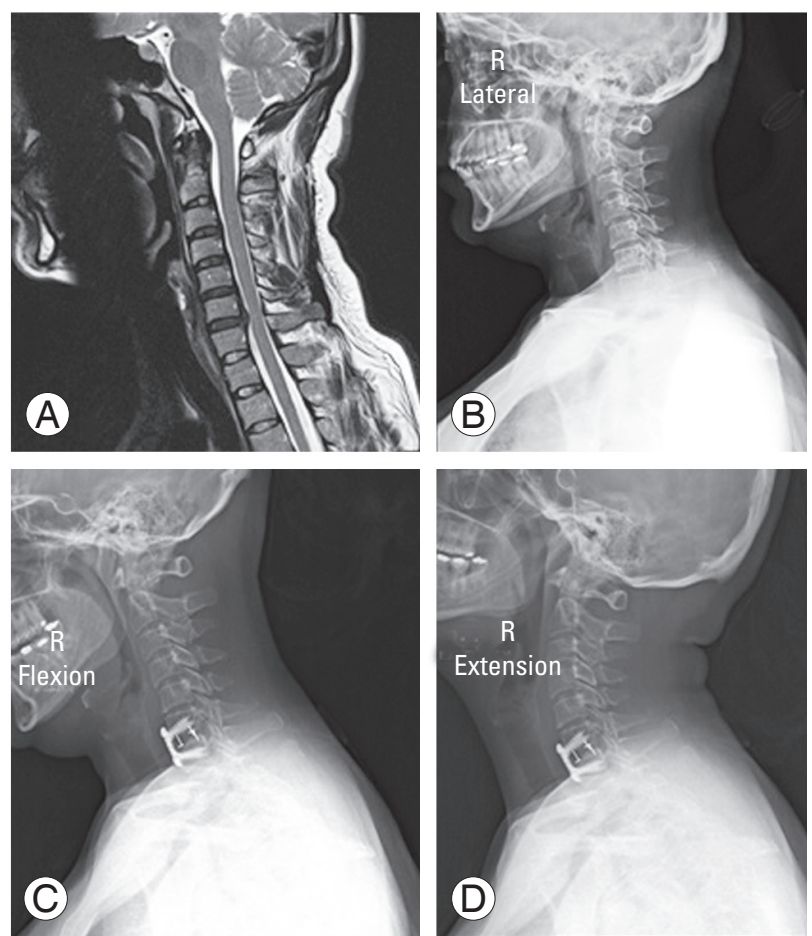

Fig. 1. A 35-year-old female patient with $\mathrm{C} 6-7$ disc herniation with central and right neuroforaminal stenosis causing right $\mathrm{C} 7$ radiculopathy failed several months of conservative management, elected to proceed with $\mathrm{C} 6-7$ anterior cervical discectomy and fusion. (A, B) Preoperative sagittal magnetic resonance imaging, lateral standing radiograph with neutral head position. (C, D) Flexion and extension lateral radiographs at 13 months postoperative demonstrating absence of spinous process motion at the level of arthrodesis and some posterior disc-space crossing trabeculation.

were used at the inferior level and variable-angle screws were used at superior levels to prevent stress-shielding [6]. Following surgery, all patients were given standardized postoperative instructions regarding neck immobilization and were instructed to wear an Aspen cervical collar for 4-6 weeks postoperatively. A representative case is demonstrated (Fig. 1).

\section{Results}

We identified 323 patients who underwent one- or twolevel ACDF between January 2015 and June 2016 and had at least 3 months of follow-up. Twenty-two patients were excluded due to prior surgery at the operative level or a second-stage planned procedure within the followup period. The final cohort included 301 patients with 435 interspaces. The average age was 54.8 years (range, 20-87 years) and $45 \%$ of patients were male. The average BMI was $30.6 \pm 7.4 \mathrm{~kg} / \mathrm{m}^{2}$; a minority of patients were diabetic (20.6\%) and current tobacco users (28.9\%) (Table 1).
Table 1. Patient demographics ( $\mathrm{N}=301)$

\begin{tabular}{lc|} 
Characteristic & Value \\
\hline Age $(\mathrm{yr})$ & $54.8 \pm 12.3$ \\
\hline Body mass index $\left(\mathrm{kg} / \mathrm{m}^{2}\right)$ & $30.6 \pm 7.1$ \\
\hline Sex & \\
\hline \multicolumn{1}{c}{ Male } & $135(44.9)$ \\
\hline Female & $166(55.1)$ \\
\hline Diabetes & $62(20.6)$ \\
\hline Smoker & $87(28.9)$ \\
\hline
\end{tabular}

Values are presented as mean \pm standard deviation for continuous variables or number (\%) for categorical variables.

Table 2. Fusion per increased interspace height ( $\mathrm{N}=435)$

\begin{tabular}{lccc}
$\Delta$ Height $(\mathrm{mm})$ & Count $(\%)$ & Fusion rate & $\begin{array}{c}95 \% \text { confidence } \\
\text { interval }\end{array}$ \\
\hline $0-1$ & $24(9.7)$ & 82.8 & $64.2-94.2$ \\
$2-3$ & $101(40.7)$ & 78.3 & $70.2-85.1$ \\
$4-5$ & $107(43.1)$ & 81.7 & $74.0-87.9$ \\
$6-8$ & $16(6.5)$ & 76.2 & $52.8-91.8$ \\
\hline
\end{tabular}

Table 3. Fusion per increased interspace level ( $N=435)$

\begin{tabular}{lccc} 
Interspace level & Count $(\%)$ & Fusion rate & $95 \%$ confidence interval \\
C2-C3 & $3(0.5)$ & 100.0 & $29.2-100.0$ \\
C3-C4 & $60(10.0)$ & 93.3 & $83.8-98.2$ \\
\hline C4-C5 & $77(12.4)$ & 89.6 & $80.6-95.4$ \\
\hline C5-C6 & $170(30.1)$ & 87.1 & $81.1-91.7$ \\
\hline C6-C7 & $115(18.9)$ & 75.7 & $66.8-83.2$ \\
\hline C7-T1 & $10(1.2)$ & 100.0 & $69.2-100.0$ \\
\hline
\end{tabular}

C2-C7, cervical interspace levels.

The fusion rate did not decrease significantly with increasing interspace height from 1 to $8 \mathrm{~mm}$ (Table 2). The fusion rate varied between $76.2 \%$ and $82.8 \%$ at a mean follow-up of $17.9 \pm 12.6$ months. An increase in interspace height of 2 to $5 \mathrm{~mm}$ with ACDF was the most common distraction achieved (84.6\%) (Table 2). The fusion rate did not differ significantly between anatomical segments from C2 to T1, with rates ranging from $75.7 \%$ to $100 \%$ (Table 3). The most common interspace for fusion was C5-C6 (30.1\%) (Table 3).

One hundred and sixty-three patients underwent one-level ACDF. Quality of life outcomes were available in these 163 patients. The mean follow-up period was 
Table 4. Quality-of-life for one level fusions by distraction ( $N=163)$

\begin{tabular}{|c|c|c|c|c|c|c|c|c|}
\hline \multirow{2}{*}{$\Delta$ Height $(\mathrm{mm})$} & \multicolumn{2}{|c|}{ NDI } & \multicolumn{2}{|c|}{ Interscapular VAS } & \multicolumn{2}{|c|}{ Neck VAS } & \multicolumn{2}{|c|}{ SF-12 } \\
\hline & Mean & $95 \% \mathrm{Cl}$ & Mean & $95 \% \mathrm{Cl}$ & Mean & $95 \% \mathrm{Cl}$ & Mean & $95 \% \mathrm{Cl}$ \\
\hline $0-1$ & 26.8 & $5.8-47.7$ & 0 & $0.0-0.0$ & 0.6 & $0.0-2.3$ & 91.9 & 73.1-110.7 \\
\hline $2-3$ & 33.8 & $25.6-42.1$ & 3.4 & $1.9-4.8$ & 4.1 & $2.9-5.3$ & 82.4 & $76.8-88.1$ \\
\hline $4-5$ & 24.5 & $15.9-33.2$ & 2.4 & $0.8-4.1$ & 3.1 & $1.6-4.6$ & 87.0 & $80.3-93.8$ \\
\hline $6-8$ & 28.3 & $6.7-49.8$ & 2.6 & $0.0-6.1$ & 4.3 & $1.4-7.3$ & 80.6 & $67.3-94.0$ \\
\hline
\end{tabular}

NDI, Neck Disability Index; VAS, Visual Analog Scale; SF-12, 12-item Short Form Health Survey; Cl, confidence interval.

Table 5. Multivariable analysis of quality-of-life

\begin{tabular}{|c|c|c|c|}
\hline Variable & $\boldsymbol{\beta}$ & $95 \% \mathrm{Cl}$ & $p$-value \\
\hline \multicolumn{4}{|l|}{ NDI } \\
\hline Age & -0.46 & -0.76 to -0.17 & $0.002^{*}$ \\
\hline $\mathrm{BMI}$ & 0.44 & -0.08 to 0.96 & 0.098 \\
\hline Sex & -4.90 & -12.05 to 2.25 & 0.178 \\
\hline No. of operative levels & -0.27 & -7.37 to 6.83 & 0.941 \\
\hline \multicolumn{4}{|l|}{ SF-12 } \\
\hline Smoking & -5.73 & -12.0 to 0.54 & 0.073 \\
\hline $\mathrm{BMI}$ & -0.34 & -0.74 to 0.06 & 0.091 \\
\hline Diabetes & -4.95 & -11.74 to 1.84 & 0.152 \\
\hline No. of operative levels & -1.814 & -7.27 to 3.64 & 0.513 \\
\hline \multicolumn{4}{|l|}{ VAS } \\
\hline Age & -0.07 & -0.11 to -0.02 & $0.005^{*}$ \\
\hline Diabetes & 0.63 & -0.73 to 1.99 & 0.360 \\
\hline BMI & 0.04 & -0.04 to 0.12 & 0.339 \\
\hline No. of operative levels & 0.22 & -0.89 to 1.33 & 0.692 \\
\hline
\end{tabular}

Cl, confidence interval; NDI, Neck Disability Index; BMI, body mass index; SF12, 12-item Short Form Health Survey; VAS, Visual Analog Scale. ${ }^{*} p<0.05$ considered significant.

16.2 \pm 13.1 months (Table 4). There was no significant correlation with interspace distraction and all PROs $(r<0.3$, $p>0.05)$. Multivariable analysis of quality of life outcomes by covariates found that age was a significant predictor of NDI $(\beta=-0.46, p=0.002)$ and VAS neck $(\beta=-0.07$, $p=0.005)$ (Table 5).

\section{Discussion}

ACDF are routinely used to treat a wide variety of cervical degenerative etiologies resulting in myelopathy and/or radiculopathy $[7,8]$. While the use of disc space distraction in ACDF is commonplace, there are no clear guidelines regarding the optimal distraction for best clinical outcomes.
We found no significant difference between the change in interspace height and postoperative NDI, VAS neck, or SF-12 scores. We also found no significant decrease in fusion rate with an increase in interspace height after distraction, regardless of height change. Our findings are consistent with a prior study by Chang et al. [4], who found no significant relationship between an increase in intervertebral space and postoperative neck and arm VAS and NDI scores. Chang et al. [4] found that the degree of preoperative neck pain correlated with the postoperative neck pain. The authors did not report the rate of radiographic fusion. Our findings demonstrated high fusion rates, consistent with previously reported rates for singleand multilevel ACDF $[9,10]$. One conclusion that can be drawn from our results is that postoperative neck pain is unlikely to be related to nonunion and is more likely multifactorial.

Another implicated source for the mechanism of postoperative neck pain is increased facet joint distraction following ACDF [3,11]. Kirzner et al. [11] found in their series that patients who had facet joint distraction of 3 $\mathrm{mm}$ or greater had significantly worse neck pain scores. They concluded that facet joint distraction of $2 \mathrm{~mm}$ was optimal [11]. Further support this was provided by Bai et al. [3], who found that a greater degree of distraction was associated with significantly increased neck pain, but there was no difference in improvement of preoperative radicular symptoms upon comparison to those with a lesser degree of distraction. This led the authors to recommend a moderate increase in intervertebral height, with a height change ratio under $10 \%$, to avoid postoperative neck pain related to over-distraction [3]. We did not find a correlation between increased interspace height and neck pain. This further suggests that disc space distraction may not be the predominant factor causing postoperative neck pain.

Some authors have expressed concern over adjacent 
segment disease and degeneration with excessive distraction in cervical spinal fusion $[12,13]$. The rapid onset of adjacent segment disease has also been associated with decreased lordosis following ACDF [14]. However, in a recent review, while excessive distraction was associated with adjacent segment disease in the lumbar spine, it was not identified as a risk factor in the cervical spine [15]. A recent study measuring 148 subaxial cervical intervertebral disc spaces found average disc height to be $5.0 \mathrm{~mm}$ in non-degenerative segments among middle-aged patients [16]. In our series, cage height ranged from 6 to $10 \mathrm{~mm}$; in essence, all patients had at least some degree of overdistraction. Our interspace height change varied from 0 to $8 \mathrm{~mm}$, with the majority of patients having a $2-3 \mathrm{~mm}$ increase in intervertebral disc height. Whether interspace distraction is a predictor of adjacent segment disease would be worth exploring in future studies.

While it is still unclear what the optimal increase in interspace height should be during ACDF, the current body of knowledge suggests that a modest degree of distraction can be tolerated to improve neuroforaminal decompression while not increasing axial neck pain $[3,4,11]$. Further supporting this, we found that increased interspace height did not increase the nonunion rate or worsen the PRO in the setting of one- to two-level ACDF with a PEEK cage. Thus, our findings suggest that a surgeon may select a cage height that adequately distracts the disc space to restore segmental lordosis and increase the size of the neural foramen with minimal risk of nonunion or worsened postoperative neck pain.

The observational nature of this study limited the ability to correlate our variables of interest with univariate analysis. Therefore, multivariate analyses were used to control for confounding factors. However, the low rate of nonunion and the moderate sample size for PRO limited the power of these analyses. We also did not have preoperative pain scores available for use in the analyses. Therefore, we excluded two-level ACDF from PRO analyses to avoid confounding two different interspace distraction values per patient PRO. Furthermore, the net response caused by the two consecutive levels treated could be more than the sum of two different levels. The result of this did yield a smaller PRO sample for analysis.

Another possible limitation was the length of followup. One series found that radiographic pseudarthrosis rates do not differ significantly beyond 12 months postoperatively; however, a more extended follow-up period may reveal other symptoms related to over-distraction and not pseudarthrosis [13]. In addition, our use of the final PRO rather than longitudinal PRO at multiple time points as our dependent variable poses another issue with the sample size. The inclusion of lordosis correction as an independent variable would also provide a complete picture to our analyses. Given the average nonunion rate of $0.9 \%-2.6 \%$ with the use of an allograft, a much larger prospective study would be required to study the association among fusion, PRO, and distraction [2].

\section{Conclusions}

Interspace distraction is patient-specific and up to $8 \mathrm{~mm}$ of distraction does not significantly worsen neck pain or increase the rate of pseudarthrosis.

\section{Conflict of Interest}

No potential conflict of interest relevant to this article was reported.

\section{Author Contributions}

Conception and design: MHL, DAC, DT, TMS. Acquisition of data: MHL, EJY, JMJ, JG, NJ, KK. Analysis and interpretation of data: MHL, DT, TMS, DAC. Drafting the article: MHL, EJY, DT, DAC. Critically revising the article: MHL, DAC, DT, TMS. Reviewed submitted version of manuscript: all authors. Statistical analysis: MHL, JG, DT. Administrative/technical/material support: KK, JG, DT. Study supervision: KK, DT, TMS, DAC.

\section{References}

1. Smith GW, Robinson RA. The treatment of certain cervical-spine disorders by anterior removal of the intervertebral disc and interbody fusion. J Bone Joint Surg Am 1958;40-A:607-24.

2. Shriver MF, Lewis DJ, Kshettry VR, Rosenbaum BP, Benzel EC, Mroz TE. Pseudoarthrosis rates in anterior cervical discectomy and fusion: a meta-analysis. Spine J 2015;15:2016-27.

3. Bai J, Zhang X, Zhang D, et al. Impact of over distraction on occurrence of axial symptom after anterior cervical discectomy and fusion. Int J Clin Exp Med 2015;8:19746-56. 
4. Chang H, Baek DH, Choi BW. The relationship between increased intervertebral disc height and development of postoperative axial neck pain after anterior cervical fusion. J Korean Neurosurg Soc 2014;55:343-7.

5. Song KS, Piyaskulkaew C, Chuntarapas T, et al. Dynamic radiographic criteria for detecting pseudarthrosis following anterior cervical arthrodesis. J Bone Joint Surg Am 2014;96:557-63.

6. Epari DR, Kandziora F, Duda GN. Stress shielding in box and cylinder cervical interbody fusion cage designs. Spine (Phila Pa 1976) 2005;30:908-14.

7. Nair R, Mendoza MC, Hsu WK. Cervical spine: anterior approach, diskectomy, and corpectomy. In: Fessler RG, Sekhar LN, editors. Atlas of neurosurgical techniques: spine and peripheral nerves. 2 nd ed. New York (NY): Thieme; 2016. p. 186-92.

8. Anderson PA, Sasso RC, Riew KD. Comparison of adverse events between the Bryan artificial cervical disc and anterior cervical arthrodesis. Spine (Phila Pa 1976) 2008;33:1305-12.

9. Fraser JF, Hartl R. Anterior approaches to fusion of the cervical spine: a metaanalysis of fusion rates. J Neurosurg Spine 2007;6:298-303.

10. Xiao SW, Jiang H, Yang LJ, Xiao ZM. Anterior cervical discectomy versus corpectomy for multilevel cervical spondylotic myelopathy: a meta-analysis. Eur Spine J 2015;24:31-9.
11. Kirzner N, Etherington G, Ton L, et al. Relationship between facet joint distraction during anterior cervical discectomy and fusion for trauma and functional outcome. Bone Joint J 2018;100-B:1201-7.

12. Li J, Li Y, Kong F, Zhang D, Zhang Y, Shen Y. Adjacent segment degeneration after single-level anterior cervical decompression and fusion: disc space distraction and its impact on clinical outcomes. J Clin Neurosci 2015;22:566-9.

13. Kaito T, Hosono N, Fuji T, Makino T, Yonenobu K. Disc space distraction is a potent risk factor for adjacent disc disease after PLIF. Arch Orthop Trauma Surg 2011;131:1499-507.

14. Alhashash M, Shousha M, Boehm H. Adjacent segment disease after cervical spine fusion: evaluation of a 70 patient long-term follow-up. Spine (Phila Pa 1976) 2018;43:605-9.

15. Hashimoto K, Aizawa T, Kanno H, Itoi E. Adjacent segment degeneration after fusion spinal surgery-a systematic review. Int Orthop 2019;43:987-93.

16. Choi SH, Lee H, Cho JH, Jung JI, Lee DH. Radiological parameters of undegenerated cervical vertebral segments in a Korean population. Clin Orthop Surg 2017;9:63-70. 